\title{
Comparison of Relative Loudness Judgment in Children using Listening Devices with Typically Developing Children
}

\author{
Shubha Tak ${ }^{10}$ Asha Yathiraj ${ }^{10}$ \\ ${ }^{1}$ Department of Audiology, All India Institute of Speech and Hearing, \\ Mysuru, Karnataka, India \\ Int Arch Otorhinolaryngol 2021;25(1):e54-e63.

\begin{abstract}
Address for correspondence Shubha Tak, Master, Department of Audiology, All India Institute of Speech and Hearing, T K Layout Manasagangothri, Mysuru MA, Karnataka 570006, India (e-mail: shubha_tak@yahoo.co.in).
\end{abstract}

\begin{abstract}
Introduction Loudness perception is considered important for the perception of emotions, relative distance and stress patterns. However, certain digital hearing devices worn by those with hearing impairment may affect their loudness perception. This could happen in devices that have compression circuits to make loud sounds soft and soft sounds loud. These devices could hamper children from gaining knowledge about loudness of acoustical signals.

Objective To compare relative loudness judgment of children using listening devices with age-matched typically developing children.

Methods The relative loudness judgment of sounds created by day-to-day objects were evaluated on 60 children ( 20 normal-hearing, 20 hearing aid users, \& 20 cochlear implant users), utilizing a standard group comparison design. Using a two-alternate forced-choice technique, the children were required to select picturized sound sources that were louder.

Results The majority of the participants obtained good scores and poorer scores were mainly obtained by children using cochlear implants. The cochlear implant users obtained significantly lower scores than the normal-hearing participants. However, the scores were not significantly different between the normal-hearing

\section{Keywords}

- relative loudness perception

- cochlear implants

- non-linear hearing aids children and the hearing aid users as well as between the two groups with hearing impairment.

Conclusion Thus, despite loudness being altered by listening devices, children using non-linear hearing aids or cochlear implants are able to develop relative loudness judgment for acoustic stimuli. However, loudness growth for electrical stimuli needs to be studied.
\end{abstract}

\section{Introduction}

Loudness judgment is utilized for several day-to-day activities. Perception of loudness has been found to help in the judgment of relative distance, ${ }^{1,2}$ emotions, ${ }^{3-5}$ and perception of stress in speech. ${ }^{6-8}$ In normal hearing children, the ability to perceive loudness similar to adults has been behaviorally observed as early as 4 to 5 years of age. ${ }^{9,10}$ received

June 17, 2019

accepted

December 21, 2019

published online

April 24, 2020
DOI https://doi.org/

$10.1055 / \mathrm{s}-0040-1702971$

ISSN 1809-9777.

\footnotetext{
(C) 2020. Fundação Otorrinolaringologia. All rights reserved.

This is an open access article published by Thieme under the terms of the Creative Commons Attribution-NonDerivative-NonCommercial-License, permitting copying and reproduction so long as the original work is given appropriate credit. Contents may not be used for commercial purposes, or adapted, remixed, transformed or built upon. (https://creativecommons.org/ licenses/by-nc-nd/4.0/)

Thieme Revinter Publicações Ltda., Rua do Matoso 170, Rio de Janeiro, RJ, CEP 20270-135, Brazil
} 
Thus, studies have demonstrated that normal hearing children develop the ability to differentiate loudness at an early age.

In individuals using hearing aids with compression, the acoustic signals are modified such that the soft sounds are made audible and the loud sounds are reduced to be within a comfortable level. ${ }^{11}$ Musa-Shufani et al ${ }^{12}$ found that with high compression ratios in hearing aids intensity differences were difficult to perceive.

Variations in the loudness of a signal has also been reported to be important for the perception of relative distance. ${ }^{1,2}$ Strybel et $\mathrm{al}^{2}$ reported that adults with normal hearing used loudness difference cues for the judgment of relative distance only when the signals were far and not when near. Ashmead et $\mathrm{al}^{1}$ also observed that adults with normal hearing were able to judge the relative distance when sound pressure cues were preserved, but had difficulty when these pressure cues were removed.

Similar to hearing aids, cochlear implants are also reported to use compression while coding sounds in the auditory system, ${ }^{13}$ which could impact the perception of loudness. A wide acoustical input dynamic range of nearly $120 \mathrm{~dB}$ is known to be coded within the limited electrical dynamic range of cochlear implants. ${ }^{14,15}$ Hence, it is possible that loudness perception may be affected in those using cochlear implants.

Further, intensity coding through cochlear implants has also found to be influenced by various features such as the microphone sensitivity, ${ }^{16}$ channel-specific gain, ${ }^{17}$ and adaptive dynamic range optimization. ${ }^{18,19}$ Loudness perception has also been found to be affected by the pulse width and phase duration used in stimulating a cochlear implant. $^{14,20-22}$ Increasing the microphone sensitivity is reported to increase the knee point and further result in the representation of low level sound within the electrical dynamic range. ${ }^{17,23,24}$ The input acoustic signals above this knee point is reported to result in infinite compression. ${ }^{17}$ In spite of increased perception of low level sounds with increase in microphone sensitivity, James et $\mathrm{al}^{16}$ found that Sprint cochlear implant users had poor preference for high microphone sensitivity setting.

Loudness perception has been evaluated with the use of adaptive dynamic range optimization (ADRO). ${ }^{18,25}$ Dawson et $\mathrm{al}^{18}$ found that, with ADRO, environmental sounds were heard more comfortably. However, James et $\mathrm{al}^{25}$ reported that $31 \%$ of their participants showed no preference to programs with or without ADRO.
Thus, from the review, it can be speculated that various programming/mapping parameters in hearing aids/cochlear implants are likely to affect loudness perception in users of these hearing devices. The literature regarding relative loudness judgement in children using listening device is relatively sparse. It is hypothesized that loudness perception in individuals using digital hearing aids and cochlear implants would be different compared with normal-hearing listeners. Loudness growth perception is recommended to be measured when selecting listening devices. ${ }^{26-28}$ However, it first needs to be established whether children with congenital hearing loss using listening devices are able to identify the relative loudness of different environmental sounds like their age-matched typically developing children. Hence, the present study aimed to compare relative loudness judgment of children using listening devices with that of age-matched typically developing children.

\section{Methods}

\section{Participants}

A total of 60 children, in the age range of 6 to 14 years old, were evaluated. Among them, 20 were typically developing children, 20 used binaural digital hearing aids, and 20 wore cochlear implants. Sample characterization is provided in -Table 1. The study was done using a standard group comparison research design. The participants were selected by the experimenters using purposive sampling. The clinical group was selected from those who visited the diagnostic center where the study was conducted. The typically developing children were recruited from schools in and around the diagnostic center. It was ensured that those using listening devices had aided thresholds well within the speech spectrum. All of the participants had normal IQ on the 'Raven's Progressive Colored Matrices'. ${ }^{29}$ The receptive language age of all of the participants was at least 5 years on the 'Receptive and Expressive Emergent Language Scale'. ${ }^{30}$ The demographic details of the hearing aid users and the cochlear implant users are given in -Table 2 and - Table 3 respectively. Prior to evaluating the participants, informed consent was obtained from the caregivers in accordance with the ethical guidance of the institute. ${ }^{31}$

The normal-hearing children had bilateral air and bone conduction thresholds $\leq 15 \mathrm{~dB}$ in the octave frequencies $250 \mathrm{~Hz}$ to $8 \mathrm{kHz}$ and $250 \mathrm{~Hz}$ to $4 \mathrm{kHz}$, respectively. None of them had any other significant history of speech and hearing, otological or medical problems.

Table 1 Sample characterizations

\begin{tabular}{|l|l|l|l|}
\hline Parameter & Normal hearing children & Haring aid users & Cochlear implant users \\
\hline Mean age (SD) & $9.25(2.23)$ & $9.25(1.51)$ & $9.85(2.95)$ \\
\hline Number of males & 9 & 13 & 12 \\
\hline Number of females & 11 & 7 & 8 \\
\hline Total number of children & 20 & 20 & 20 \\
\hline
\end{tabular}

Abbreviation: SD, standard deviation. 
Table 2 Demographic details of the participants using hearing aids

\begin{tabular}{|c|c|c|c|c|c|c|c|c|}
\hline \multirow[t]{2}{*}{ Participant } & \multirow{2}{*}{$\begin{array}{l}\text { Age } \\
\text { (Years old) }\end{array}$} & \multirow[t]{2}{*}{ Gender } & \multirow{2}{*}{$\begin{array}{l}\text { No. of Years hearing } \\
\text { aids were used }\end{array}$} & \multicolumn{5}{|c|}{ Aided thresholds (in dB) } \\
\hline & & & & Ear & $500 \mathrm{~Hz}$ & $1 \mathrm{kHz}$ & $2 \mathrm{kHz}$ & $4 \mathrm{kHz}$ \\
\hline \multirow[t]{2}{*}{1} & \multirow[t]{2}{*}{11} & \multirow[t]{2}{*}{ Female } & \multirow[t]{2}{*}{8} & $\mathrm{R}$ & 40 & 55 & 65 & 70 \\
\hline & & & & $\mathrm{L}$ & 25 & 25 & 50 & 50 \\
\hline \multirow[t]{2}{*}{2} & \multirow[t]{2}{*}{6} & \multirow[t]{2}{*}{ Male } & \multirow[t]{2}{*}{4} & $\mathrm{R}$ & 25 & 30 & 35 & 40 \\
\hline & & & & $\mathrm{L}$ & 20 & 30 & 30 & 35 \\
\hline \multirow[t]{2}{*}{3} & \multirow[t]{2}{*}{9} & \multirow[t]{2}{*}{ Female } & \multirow[t]{2}{*}{5} & $\mathrm{R}$ & 35 & 40 & 40 & 40 \\
\hline & & & & $\mathrm{L}$ & 40 & 25 & 35 & 40 \\
\hline \multirow[t]{2}{*}{4} & \multirow[t]{2}{*}{9} & \multirow[t]{2}{*}{ Male } & \multirow[t]{2}{*}{4} & $R$ & 25 & 30 & 25 & 30 \\
\hline & & & & $\mathrm{L}$ & 25 & 30 & 30 & 35 \\
\hline \multirow[t]{2}{*}{5} & \multirow[t]{2}{*}{9} & \multirow[t]{2}{*}{ Male } & 7 & $\mathrm{R}$ & 25 & 25 & 30 & 35 \\
\hline & & & & $\mathrm{L}$ & 20 & 25 & 25 & 30 \\
\hline 6 & 8 & Female & 7 & $R$ & 30 & 35 & 40 & 40 \\
\hline & & & & $\mathrm{L}$ & 35 & 35 & 30 & 35 \\
\hline 7 & 11 & Male & 6 & $\mathrm{R}$ & 30 & 40 & 45 & 45 \\
\hline & & & & $\mathrm{L}$ & 30 & 40 & 30 & 30 \\
\hline 8 & 9 & Male & 7 & $\mathrm{R}$ & 30 & 30 & 35 & 40 \\
\hline & & & & $\mathrm{L}$ & 30 & 30 & 40 & 50 \\
\hline 9 & 11 & Female & 7 & $\mathrm{R}$ & 35 & 45 & 40 & 50 \\
\hline & & & & $\mathrm{L}$ & 40 & 45 & 40 & 45 \\
\hline 10 & 9 & Female & 5 & $\mathrm{R}$ & 25 & 25 & 35 & 50 \\
\hline & & & & $\mathrm{L}$ & 30 & 30 & 35 & 45 \\
\hline 11 & 8 & Male & 6 & $\mathrm{R}$ & 35 & 40 & 45 & 60 \\
\hline & & & & $\mathrm{L}$ & 40 & 40 & 35 & 60 \\
\hline 12 & 11 & Male & 7 & $R$ & 30 & 25 & 30 & 25 \\
\hline & & & & $\mathrm{L}$ & 35 & 35 & 40 & 35 \\
\hline 13 & 12 & Male & 2 & $R$ & 25 & 25 & 35 & 30 \\
\hline & & & & $\mathrm{L}$ & 30 & 30 & 35 & 30 \\
\hline 14 & 11 & Male & 8 & $R$ & 30 & 25 & 25 & 30 \\
\hline & & & & $\mathrm{L}$ & 25 & 25 & 25 & 20 \\
\hline 15 & 9 & Female & 7 & $\mathrm{R}$ & 40 & 45 & 35 & 50 \\
\hline & & & & $\mathrm{L}$ & 40 & 40 & 45 & 45 \\
\hline 16 & 8 & Male & 2 & $R$ & 40 & 40 & 40 & 50 \\
\hline & & & & $\mathrm{L}$ & 40 & 40 & 45 & 55 \\
\hline 17 & 10 & Male & 8 & $\mathrm{R}$ & 30 & 35 & 40 & 35 \\
\hline & & & & $\mathrm{L}$ & 35 & 35 & 40 & 35 \\
\hline 18 & 8 & Male & 6 & $\mathrm{R}$ & 30 & 25 & 45 & 50 \\
\hline & & & & $\mathrm{L}$ & 45 & 30 & 40 & 55 \\
\hline 19 & 7 & Female & 3 & $\mathrm{R}$ & 35 & 40 & 35 & 50 \\
\hline & & & & $\mathrm{L}$ & 30 & 45 & 45 & 50 \\
\hline 20 & 9 & Male & 8 & $\mathrm{R}$ & 40 & 30 & 30 & 45 \\
\hline & & & & $\mathrm{L}$ & 25 & 30 & 30 & 40 \\
\hline
\end{tabular}

Abbreviations: L, Left ear; R, Right ear. 


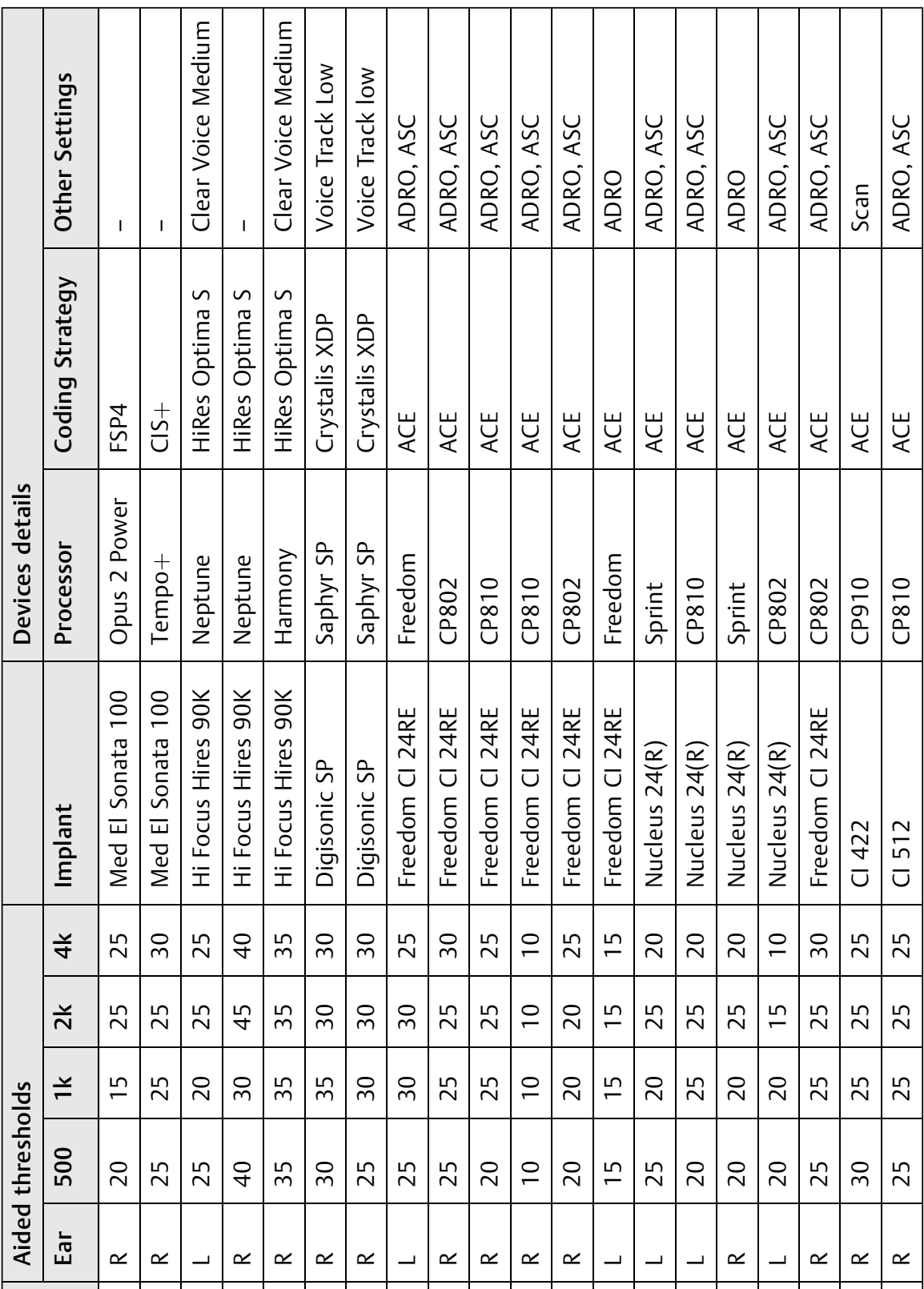

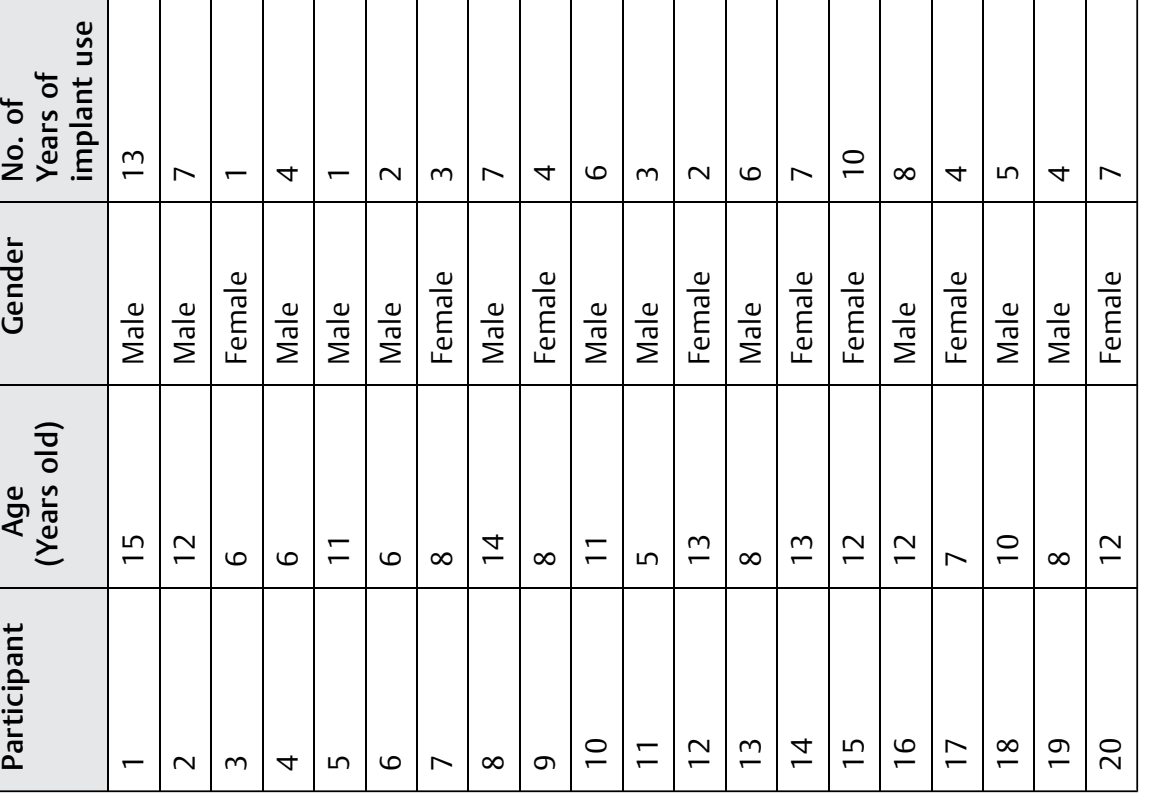


Among the children using hearing aids, four had profound hearing loss and one had moderate hearing loss. The remaining had moderately-severe to severe hearing loss (mean $\mathrm{PTA}=74.79 \mathrm{~dB} \quad \mathrm{HL}$; standard deviation $[\mathrm{SD}]=13.15$; range $=43.33$ to $103.33 \mathrm{~dB} \mathrm{HL}$ ). All but 2 had symmetrical hearing loss, with the mean aided thresholds for $500 \mathrm{~Hz}$, $1,000 \mathrm{~Hz}, 2,000 \mathrm{~Hz}$ and $4,000 \mathrm{~Hz}$ being $36.16 \mathrm{~dB} \mathrm{HL}$, SD being 6.78 and the range being 23.75 to $57.50 \mathrm{~dB} \mathrm{HL}$ (-Table 2). They used binaural digital behind-the-ear hearing aids. The compression ratio used by all of the participants varied from 1.6:1 to $3.2: 1$, based on the recommendation of audiologists. The age at which the children started utilizing their hearing aids ranged from 1 to 10 years old, with the mean age being 3.45 years old. Although a few of the children started using their hearing aids late, they were able to develop a fairly high level of language due to the degree of hearing loss being lower. The number of years of use of the hearing aids ranged from 2 to 8 years. Only participants who consistently used binaural hearing aids were included in the study.

The children using cochlear implants wore their device in one ear for a minimum of 1 year and had stable maps. Among them, 13 children also wore a behind-the-ear hearing aid in the non-implanted ear. The mean aided threshold for $500 \mathrm{~Hz}$, $1,000 \mathrm{~Hz}, 2,000 \mathrm{~Hz}$ and $4,000 \mathrm{~Hz}$ of the participants using cochlear implants was $24.44 \mathrm{~dB}$ HL, with SD being 6.52 and the range being 10 to $38 \mathrm{~dB} \mathrm{HL}$ ( - Table 3 ). Among those who wore hearing aids in the nonimplanted ear, the mean aided threshold for $500 \mathrm{~Hz}, 1,000 \mathrm{~Hz}, 2,000 \mathrm{~Hz}$ and $4,000 \mathrm{~Hz}$ was $58.83 \mathrm{~dB}$ HL with SD being 20.08 and the range being 37.5 to 101.25 dB HL. The cochlear implants worn by the participants varied. Among them 2 used Med-EL devices (Innsbruck, Tyrol, Austria), 3 used Advanced Bionics devices (Los Angeles, California, USA), 2 used Neurelec devices (Vallauris, France) and 13 used Cochlear Nucleus devices (Sydney, NSW, Australia). The age at which children started using cochlear implant ranged from 2 to 11 years old (mean $=4.65$ years). The number of years of use of the cochlear implant ranged from 1 to 13 years, with only 2 participants using their device for 1 year.

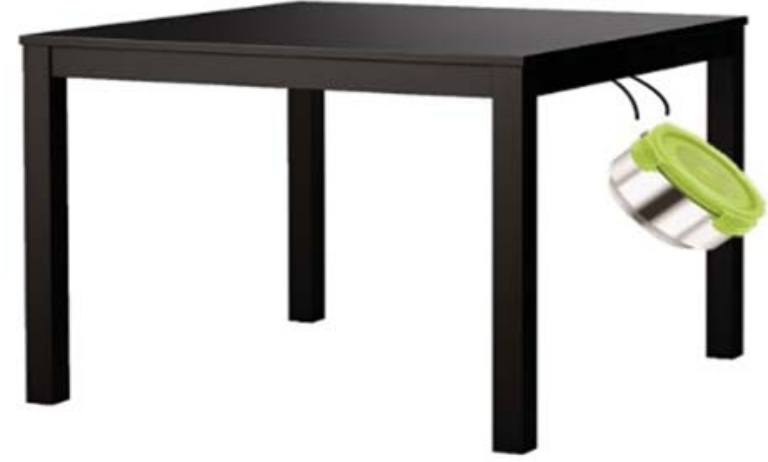

\section{Material}

To evaluate relative loudness judgment, a test was developed. The 'Relative Loudness Judgment Test' consisted of 30 sets of stimuli, each consisting of two pictures depicting sounds produced by common objects/situations ( - Fig. 1). Initially, 38 of these pairs were developed and 10 normal-hearing adults were required to judge whether the stimuli in each pair produced distinctly different loudness. Based on their responses, three pairs that were considered ambiguous were excluded from the test. The remaining 35 stimulus pairs were pictorially depicted, with each picture having a dimension of $12 \times 10 \mathrm{~cm}$. A total of 25 adults, who had not judged the material earlier, were instructed to describe what the pictures indicated as well as to judge whether the objects/situations in each pictorial pair depicted distinctly different loudness. These adults included parents of typically developing children, parents of children with hearing impairment, and speech and hearing professionals. As three of the pictures were labeled as being ambiguous, they were eliminated and the final 'Relative Loudness Judgment Test' contained 32 pairs of stimuli, of which 2 pairs served as practice stimuli.

Further, the selected 30 pairs of test stimuli were categorized as being 'grossly different' and 'finely different'. This categorization was based on the responses of 10 adult participants. 'Grossly different' stimuli were those pairs of stimuli that were considered to have distinctly different loudness by at least $80 \%$ of the adults. The 'finely different' stimuli included pairs that were considered as having fine difference in loudness by at least $80 \%$ of the participants and pairs having no consensus as being gross or finely different. From the responses of the participants, 17 stimulus pairs were labeled as 'Grossly different' and 13 were considered to be 'Finely different'. Description of the test stimuli are provided in -Appendix $\mathbf{A}$.

\section{Instrument and Environment}

To determine the hearing status of the participants, a Piano diagnostic audiometer (Inventis, Padova, Italy) was used. The absence of any middle ear pathology was confirmed

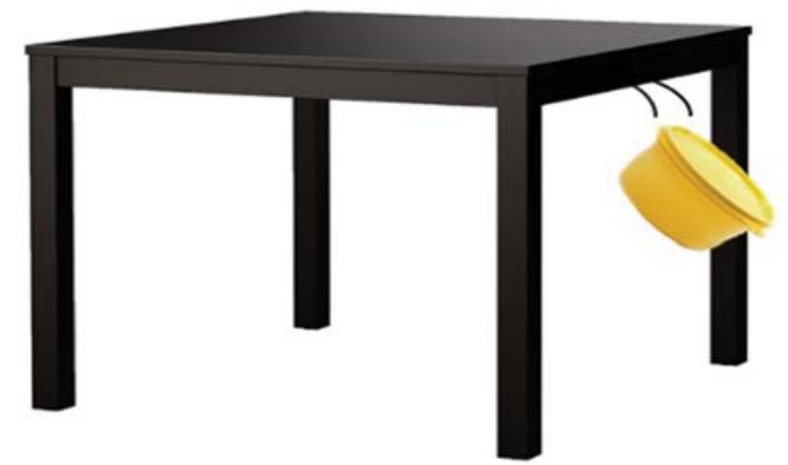

Fig. 1 Sample of a stimulus-pair used in the 'Relative loudness judgment test', with the figure in the left depicting the louder stimulus. 
with the help of a GSI Tympstar immittance audiometer (Grason-Stadler, Eden Prairie, MN, USA). A HP Envy Laptop (Intel Core i7) (Hewlett-Packard, Palo Alto, CA, USA), loaded with the software 'Paradigm' (v2.5.0.68) designed by Tagliaferri ${ }^{32}$ was used to test relative loudness judgment.

The audiological tests were performed in a sound-treated suite that met the specification of ANSI/ASA S3.1-1999 ${ }^{33}$ The loudness testing was performed in a distraction-free quiet room.

\section{Procedure}

Those participants who met the participant selection criteria were subjected to further evaluation. The children were reported to use their prescribed hearing aids/cochlear implants regularly in the settings recommended by qualified audiologists.

All of the participants were tested with 32 pairs of stimuli (2 practice and 30 test stimuli). The pairs of stimuli were presented through the Paradigm software, loaded in the laptop, kept at a distance of $0.5 \mathrm{~m}$ and at $0^{\circ}$ azimuth from the head of the participants. Pairs of pictures were presented one after the other and the participants were instructed to point or click on the picture that depicted the louder sound. If a child could not use the computer mouse, the examiner clicked on the selected picture. Those who had difficulty with the practice items were reinstructed and it was once again demonstrated what they were expected to do. The time taken to evaluate each child was $\sim 10$ minutes and the testing was done in a single session. The Paradigm software was programmed to automatically assign a score of 1 for each correct response and of 0 for each incorrect response. Thus, the maximum possible score that could be obtained was 30 . Test-retest reliability was done on $10 \%$ of the participants, with representation from all three groups.

\section{Analyses}

Descriptive and inferential statistics were conducted using IBM SPSS Statistics for Windows. Version 21 (IBM Corp., Armonk, NY, USA). The Shapiro-Wilk test performed to check the normality indicated that the data were not normally distributed $(p<0.05)$, hence nonparametric statistics was done. Both descriptive and inferential statistics were done.

\section{Results}

The results are provided to depict the comparison of the relative loudness judgment between the participant groups (normal-hearing children, children using hearing aids, and children using cochlear implants). Additionally, comparison of scores for the 'grossly different' and 'finely different' stimulus-pairs within each group as well as between the three participant groups are given. The relationship between the duration of experience with the listening device and relative loudness judgment scores are also presented.

\section{Comparison of Relative Loudness between the Participant Groups}

The means and SDs as well as medians and ranges of the overall scores for the 30 test items are depicted for the 3 participant groups in -Table 4 . It can be noted from the table that the relative loudness judgment scores for all the participants approximated the maximum possible score. However, the median scores obtained for the normal hearing children was higher than that of the hearing aid users and the cochlear implant users. The range was also found to be higher in the clinical population when compared with the normal-hearing group.

The Kruskal-Wallis test of significance was conducted to compare the ability of the three participant groups to judge relative loudness. The results revealed that there was a significant difference in the ability to judge relative loudness between the three groups $[H(2)=7.29, p=0.02]$. Furthermore, to determine which of the pairs of groups differed from each other, Mann-Whitney $U$ tests were performed. The ability to judge relative loudness did not significantly differ between the normal-hearing listeners and the hearing aid users $[U=139.00, p=0.06, r=-0.29]$ as well as between children using hearing aids and children using cochlear implants $[U=164.00, p=0.29, r=-0.17]$. However, a significant difference was observed between the typically developing children and the children using cochlear implants $[U=113.00, p=0.01, r=-0.42]$ (-Table 4).

\section{Comparison of Grossly Different and Finely Different Stimulus-pairs within each Group}

Within each participant group, the relative loudness judgment scores for stimuli that were categorized as 'Grossly

Table 4 Comparison of normal hearing children, children using hearing aids and children using cochlear implants

\begin{tabular}{|l|l|l|l|l|l|l|}
\hline Participant Groups & $\boldsymbol{n}$ & Mean\# & SD & Median & Range & p-value \\
\hline Normal hearing & 20 & 29.60 & 0.60 & 30.00 & 28 to 30 & 0.06 \\
\hline Hearing aid users & 20 & 29.10 & 1.12 & 29.00 & 25 to 30 & 28 to 30 \\
\hline Normal hearing & 20 & 29.60 & 0.60 & 30.00 & 22 to 30 & $0.008^{*}$ \\
\hline Cochlear implant users & 20 & 28.35 & 2.00 & 29.00 & 29 to 30 & 0.29 \\
\hline Hearing aid users & 20 & 29.10 & 1.12 & 29.00 & 29.00 & to 30 \\
\hline Cochlear implant users & 20 & 28.35 & 2.00 & & & \\
\hline
\end{tabular}

Abbreviations: $n$, number of participants; SD, standard deviation.

Note: \# Maximum possible score = 30; "Mann-Whitney $U$ test results with Bonferroni correction for 3 comparisons. 
Table 5 Comparison of percentage scores of 'Grossly different' and 'Finely different' stimulus-pairs within each group

\begin{tabular}{|l|l|l|l|l|l|l|}
\hline Participant Groups & Loudness difference of stimulus-pairs & Mean \% & SD & Median \% & Range & $p$-value \\
\hline \multirow{2}{*}{ Normal Hearing } & Grossly different & 98.82 & 2.41 & 100 & 5.88 & 0.49 \\
\cline { 2 - 6 } & Finely different & 98.46 & 4.02 & 100 & 15.38 & 17.65 \\
\hline \multirow{2}{*}{$\begin{array}{l}\text { Hearing } \\
\text { aid users }\end{array}$} & Grossly different & 96.76 & 4.86 & 100 & 15.46 \\
\cline { 2 - 7 } & Finely different & 96.53 & 4.65 & 100 & 23.53 \\
\hline \multirow{2}{*}{ Cochlear implant users } & Grossly different & 93.82 & 6.74 & 94.11 & 23.53 \\
\cline { 2 - 7 } & Finely different & 95.00 & 7.60 & 100 & 30.77 \\
\hline
\end{tabular}

Abbreviation: SD, standard deviation.

Notes: *Wilcoxon signed rank tests, significance level $=0.05 ; r=$ effect size.

different' were compared with stimuli that were categorized as 'Finely different'. As there were unequal numbers of stimulus-pairs between the two categories (gross and fine), the scores were converted into percentages. - Table 5 represents the mean, $\mathrm{SD}$, median and range of the percentage scores.

It was noted that in the normal-hearing children the mean percentage scores for the 'Finely different' category was marginally poorer than for the 'Grossly different' category. However, the 'Finely different' category tended to have more variability than the 'Grossly different' category. Likewise, the mean scores in the two groups with hearing impairment differed marginally across the two levels of difficulty. On the other hand, the variability between the two levels of difficulty did not differ much in both groups of children with hearing impairment.

Furthermore, to establish whether the scores were statistically different, a Wilcoxon signed rank test was done within each group to compare the percentage scores between categories. It was noted that there was no significant difference between the two categories within each group ( - Table 5 ).

\section{Comparison of Grossly and Finely Different Stimuli- pairs between Participant Groups}

The Kruskal-Wallis test of significance was conducted to compare the relative loudness judgment scores across the three participant groups for the stimuli categorized as 'Grossly different' and 'Finely different'. The results indicated that there was a significant difference among the three groups for the 'Grossly different' stimuli $[H(2)=8.392, p=0.015]$, but not for the 'Finely different' stimuli $[H(2)=4.260, p=0.119]$. Since there was a significant difference between the groups for the 'Grossly different' stimuli, further analysis was done and no further analysis was done for the 'Finely different' stimuli.

Pair-wise comparisons of the groups using MannWhitney U tests revealed that for the 'Grossly different' stimuli there was no significant difference between the typically developing children and children using hearing aids $[U=156.00, p=0.242, r=-0.234]$. Also, there was no significant difference in the judgment of relative loudness between children using hearing aids and children using cochlear implants $[U=148.500, p=0.165, r=-0.24]$. However, there was a statistically significant difference between the typically developing children and children using cochlear implants [ $U=108.00, p=0.012, r=0.449]$.

\section{Relation between the Duration of Usage of Listening Device and Relative Loudness Judgment}

To study if a correlation exists between duration of useful listening experience with the hearing devices and the ability to judge relative loudness, the Spearman correlation was done. For the typically developing children, the hearing experience was calculated as their chronological age. With all three groups combined, no significant correlation was observed between the duration of listening experience and the overall scores obtained on the relative loudness judgment test $\left[r_{s}(58)=0.22\right.$, $p>0.05$ ]. Similarly, the correlation remained poor for the typically developing children $\left[r_{s}(18)=0.12, p>0.05\right]$, children using hearing aids $\left[r_{s}(18)=-0.28, p>0.05\right]$, and children using cochlear implants $\left[r_{s}(18)=0.14, p>0.05\right]$.

The correlation of years of experience with the listening devices was also studied for the 'Grossly different' and the 'Finely different' stimuli for each group of participants separately. For the 'Grossly different' stimuli, the correlation was poor for the typically developing children $\left[r_{s}(18)=0.294\right.$, $p>0.05]$, children using hearing aids $\left[r_{s}(18)=0.212, p>0.05\right]$ and children using cochlear implants $\left[r_{s}(18)=0.253, p>0.05\right]$. Likewise, for the 'Finely different' stimuli, the correlation was poor for the typically developing children $\left[r_{s}(18)=-0.119\right.$, $p>0.05]$, children using hearing aids $\left[r_{s}(18)=-0.559\right.$, $p>0.05]$ and children using cochlear implants $\left[r_{s}(18)=0.077\right.$, $p>0.05]$.

The responses of the $10 \%(n=6)$ of the participants on whom the 'Relative loudness judgment test' was repeated were analyzed using Cronbach $\alpha$. As the $\alpha$ value was 0.81 , it indicated that the test-retest reliability was high. Also, the percentage of agreement between their responses was calculated. It was found to range between $90 \%$ to $100 \%$, indicating a good test-retest agreement.

Thus, the findings of the study indicated that a statistically significant difference in relative loudness judgment scores was observed between the typically developing children and the children using cochlear implants. However, no such difference was obtained between the typically developing children and those using hearing aids, as well as between the two groups with hearing impairment. All of the three participant groups demonstrated no significant difference in 
perceiving the 'Grossly different' and 'Finely different' pairs of stimuli. However, there was a statistically significant difference when the scores of 'grossly different' stimuli were compared between the typically developing children and the children using cochlear implants. Furthermore, it was noted that there was no correlation between the experience with the listening device and the loudness judgment scores obtained.

\section{Discussion}

The results of the study are discussed with reference to the comparison of the relative loudness judgment between the participant groups (20 normal-hearing children, 20 children using hearing aids, and 20 children using cochlear implants); comparison of scores for the 'Grossly different' and 'Finely different' stimuli pairs within each group, as well as between the three participant groups; and the relationship between the duration of experience with the listening device and relative loudness judgment scores.

\section{Comparison of Relative Loudness Judgment between the Participant Groups}

All of the three groups of children obtained fairly high scores on the 'Relative loudness judgment test', there being no statistically significant difference between the typically developing children and those using hearing aids. This indicates that despite the hearing aids being non-linear and compressing the acoustical signals, children using these devices aids were able to perceive relative loudness like their normalhearing peers.

This finding in the present study is supported by Shi et $\mathrm{al}^{34}$ who found that adults using hearing aids were able to perceive the loudness of environmental sounds. Also, it was noted by Schmidt et al $^{35}$ that children using hearing aids could use the intensity cues to perceive emotions similar as normal-hearing listeners.

Thus, it can be construed that non-linear hearing aids do not hamper the perception of loudness of sounds. Children using these devices are able to develop knowledge of the relative loudness of different signals in the environment. Hence, administering tests of loudness growth, as a part of hearing aid selection/fitment, can be performed on those who are at least 6 years old.

However, in the current study, children using cochlear implants were found to have significantly poorer judgment of relative loudness compared with the normal-hearing children. A possible reason for the children using cochlear implants having poorer relative loudness judgment could be due to them having a higher differential limen for intensity. Adults using cochlear implants have been reported earlier to have a higher differential limen for intensity as compared with normal-hearing individuals by Nikakhlagh et al. ${ }^{36}$ It is possible that, like adults, children using cochlear implants also have a higher difference limen for intensity.

Further, cochlear implants are known to have algorithms that make soft sounds loud and loud sounds soft. ${ }^{37}$ The majority of the children evaluated in the current study used cochlear implants that utilized these algorithms. This could have affected their loudness judgment abilities. However, all but one child using cochlear implants obtained scores that were $>80 \%$. This indicates that despite performing poorer than typically developing children, these children also had fairly good relative loudness judgment abilities.

\section{Comparison of 'Grossly Different' and 'Finely Different' Stimuli-pairs within and between Participant Groups}

Within all three participant groups, no significant difference was observed between the scores for 'Grossly different' and 'Finely different' stimuli. This indicates that children are able to perceive relative loudness in a similar manner even if the loudness of pairs of stimuli is not very different or is difficult to judge. However, across the participant groups, a significant difference was seen between the typically developing children and the children using cochlear implants only for the 'Grossly different' stimuli and not for the 'Finely different' stimuli. This could have happened as the variability in scores for the 'Grossly different' stimuli were the least in the typically developing children, but was relatively much higher in the children using cochlear implants. This difference in variability between the two groups could have resulted in the significant difference for this category of stimuli. Thus, although adults categorized some of the stimuli as being grossly different and others as being finely different, all of the children perceived them with equal ease. However, the children using cochlear implants demonstrated varied loudness judgment responses. On examination of the raw data of the children using cochlear implants, it was observed that that the children with poorer scores varied in terms of the company/model that they used. Hence, the poorer performance in a section of the children using cochlear implants cannot be attributed to the features in the device worn by them.

\section{Relation between the Duration of Experience with the Listening Device and Relative Loudness Judgment}

The duration of hearing device usage was found to have no significant effect on the relative loudness judgment ability of children. This was seen in all three groups. It can be inferred from the findings of the study that children using hearing aids for just 2 years or children using cochlear implants for just 1 year are able to make judgments about loudness of stimuli in the environment.

\section{Conclusions}

The findings of the study revealed that children with hearing impairment using cochlear implants are not able to develop the ability to judge relative loudness to the same extent as typically developing children. However, children using nonlinear hearing aids were able to respond similarly to typically developing children. Despite the children with cochlear implants performing poorer than the typically developing children, they obtained fairly high scores indicating that they did have the ability to judge relative loudness. 


\section{Appendix A}

\section{Relative Loudness Judgment Test: Stimuli Description}

Practice stimuli

1. Plastic spoon falling off a table versus Steel spoon falling off a table

2. Soldier walking on road versus Soldier walking on grass

Test stimuli

3. Door knock using knuckles versus Door bell ring (Gross difference)

4. Currency note falling on a floor versus Coin falling on a floor (Gross difference)

5. Blender / Mixer noise versus Fan noise (Gross difference)

6. Steel tiffin box falling off a table versus Plastic tiffin box falling off a table (Fine difference)

7. Beating drum versus Girl singing (Gross difference)

8. Man jumping on road versus Man walking on road (Fine difference)

9. Key falling directly on a floor versus Key falling on a carpet (Fine difference)

10. Ball of wool falling versus Football falling (Fine difference)

11. Tumbler falling on sand versus Tumbler falling on floor (Gross difference)

12. Writing with a pencil versus Sharpening a pencil (Fine difference)

13. Fan noise versus Blowing whistle (Gross difference) 14. Pouring tea in a cup versus Filling bucket with water (Fine difference)

15. Leaves falling off a tree versus Bird chirping (Fine difference)

16. Baby crying versus Baby cooing (Gross difference) 17. Brushing teeth versus Combing hair (Fine difference)

18. Dog barking versus Sheep bleating (Fine difference) 19. Steel glass falling on a bed versus Steel glass falling off a bed on a floor (Gross difference)

20. Napkin falling off a bed versus Books falling off a bed (Gross difference)

21. Girls whispering versus Child screaming (Gross difference)

22. Bouncing a ball versus Rolling a ball (Fine difference)

23. Coin falling off a table versus Eraser falling off a table (Fine difference)

24. Rolling chapati versus Pressure cooker whistle (Gross difference)

25 . Baby laughing versus Baby crying (Fine difference)

26. Child playing with a toy car versus Child beating a drum (Gross difference)

27. Lady walking barefooted versus Lady walking with stilettos (Gross difference)

28. Falling cup on a floor versus Pouring tea in a cup (Gross difference)
29. Water falling versus Water flowing (Fine difference)

30. Ball falling on a floor versus Ball falling on grass (Gross difference)

31. Plastic plate falling from a table versus Steel plate falling from a table (Gross difference)

32. Rain water falling on the roof of a house versus Rain falling on a grass patch (Gross difference)

Conflict of Interests

The authors have no conflict of interests to declare.

\section{References}

1 Ashmead DH, LeRoy D, Odom RD. Perception of the relative distances of nearby sound sources. Percept Psychophys 1990;47 (04):326-331. Doi: 10.3758/BF03210871

2 Strybel TZ, Perrott DR. Discrimination of relative distance in the auditory modality: the success and failure of the loudness discrimination hypothesis. J Acoust Soc Am 1984;76(01):318-320. Doi: $10.1121 / 1.391064$

3 House D. On the perception of mood in speech: Implications for the hearing impaired. Phonum; 1990:99-108

4 Schmidt J, Janse E, Scharenborg O. Perception of Emotion in Conversational Speech by Younger and Older Listeners. Front Psychol 2016;7:781. Doi: 10.3389/fpsyg.2016.00781

5 Laukkanen A-M, Vilkman E, Alku P, Oksanen H. Physical variations related to stress and emotional state: a preliminary study. J Phonetics 1996;24(03):313-335

6 Fry DB. Duration and intensity as physical correlates of linguistic stress. J Acoust Soc Am 1955;27(04):765-768. Doi: $10.1121 / 1.1908022$

7 Fry DB. Experiments in the perception of stress. Lang Speech 1958;1(02):126

8 Lieberman P. Some acoustic correlates of word stress in American English. J Acoust Soc Am 1960;32(04):451-454. Doi: 10.1121/1.1908095

9 Collins AA, Gescheider GA. The measurement of loudness in individual children and adults by absolute magnitude estimation and cross-modality matching. J Acoust Soc Am 1989;85(05): 2012-2021. Doi: 10.1121/1.397854

10 Serpanos YC, Gravel JS. Assessing growth of loudness in children by cross-modality matching. J Am Acad Audiol 2000;11(04): 190-202

11 Dillon H. Hearing Aids. United States of America: Thieme; 2001

12 Musa-Shufani S, Walger M, von Wedel H, Meister H. Influence of dynamic compression on directional hearing in the horizontal plane. Ear Hear 2006;27(03):279-285

13 Moore BC. Coding of sounds in the auditory system and its relevance to signal processing and coding in cochlear implants. Otol Neurotol 2003;24(02):243-254

14 Zeng F-G, Galvin JJ III, Zhang C. Encoding loudness by electric stimulation of the auditory nerve. Neuroreport 1998;9(08): 1845-1848

15 Zeng F-G, Galvin JJ III. Amplitude mapping and phoneme recognition in cochlear implant listeners. Ear Hear 1999;20(01):60-74

16 James CJ, Skinner MW, Martin LF, et al. An investigation of input level range for the nucleus 24 cochlear implant system: speech perception performance, program preference, and loudness comfort ratings. Ear Hear 2003;24(02):157-174. Doi: 10.1097/01. AUD.0000058107.64929.D6

17 Vaerenberg B, Govaerts PJ, Stainsby T, Nopp P, Gault A, Gnansia D. A uniform graphical representation of intensity coding in currentgeneration cochlear implant systems. Ear Hear 2014;35(05): 533-543. Doi: 10.1097/AUD.0000000000000039 
18 Dawson PW, Decker JA, Psarros CE. Optimizing dynamic range in children using the nucleus cochlear implant. Ear Hear 2004;25 (03):230-241. Doi: 10.1097/01.AUD.0000130795.66185.28

19 Müller-Deile J, Kiefer J, Wyss J, Nicolai J, Battmer R. Performance benefits for adults using a cochlear implant with adaptive dynamic range optimization (ADRO): a comparative study. Cochlear Implants Int 2008;9(01):8-26. Doi: 10.1179/cim.2008.9.1.8

20 Chatterjee M, Fu Q-J, Shannon RV. Effects of phase duration and electrode separation on loudness growth in cochlear implant listeners. J Acoust Soc Am 2000;107(03):1637-1644. Doi: $10.1121 / 1.428448$

21 Pfingst BE, Miller AL, Morris DJ, Zwolan TA, Spelman FA, Clopton BM. Effects of electrical current configuration on stimulus detection. Ann Otol Rhinol Laryngol Suppl 1995;166:127-131

22 Smith DW, Finley CC. Effects of electrode configuration on psychophysical strength-duration functions for single biphasic electrical stimuli in cats. J Acoust Soc Am 1997;102(04):2228-2237. Doi: 10.1121/1.419636

23 Wolfe J, Schafer EC, John A, Hudson M. The effect of front-end processing on cochlear implant performance of children. Otol Neurotol 2011;32(04):533-538. Doi: 10.1097/MAO.0b013e318210b6ec

24 Spahr AJ, Dorman MF, Loiselle LH. Performance of patients using different cochlear implant systems: effects of input dynamic range. Ear Hear 2007;28(02):260-275. Doi: 10.1097| AUD.0b013e3180312607

25 James CJ, Blamey PJ, Martin L, Swanson B, Just Y, Macfarlane D. Adaptive dynamic range optimization for cochlear implants: a preliminary study. Ear Hear 2002;23(01):49S-58S

26 Palmer C, Valente M, Powers T, Mueller H, Eds. The impact of restoring normal loudness growth on speech understanding as a function of signal-to-noise ratio and input level. NIH/VA Hearing Aid Research and Development Conference, Bethesda, MD; 1997
27 Valente M, Van Vliet D. The independent hearing aid fitting forum (IHAFF) protocol. Trends Amplif 1997;2(01):6-35. Doi: $10.1177 / 108471389700200102$

28 Kiessling J, Schubert M, Archut A. Adaptive fitting of hearing instruments by category loudness scaling (ScalAdapt). Scand Audiol 1996;25(03):153-160

29 Raven J. Raven progressive matrices. Handbook of nonverbal assessment: Springer; 2003:223-237

30 Bzoch KR, League R. Receptive-expressive emergent language scale: Pro-ed; 1991

31 All India Institute of Speech and Hearing. Ethical guidelines for Bio-behavioural research involving human subjects. Mysore: All India Institute of Speech and Hearing; 2009

32 Tagliaferri B Paradigm. Perception Research Systems. Inc www perceptionresearchsystems com. 2005

33 ANSI/ASA S3.1-1999. American national standard maximum permissible ambient noise levels for audiometric rooms.: Standards Secretariate, Acoustical Society of America; R2013.

34 Shi LF, Doherty KA, Zwislockit JJ. Aided loudness growth and satisfaction with everyday loudness perception in compression hearing aid users. J Am Acad Audiol 2007;18(03):206-219

35 Schmidt J, Herzog D, Scharenborg O, Janse E. Do Hearing Aids Improve Affect Perception? Adv Exp Med Biol 2016;894:47-55. Doi: 10.1007/978-3-319-25474-6_6

36 Nikakhlagh S, Saki N, Karimi M, Mirahmadi S, Rostami MR. Evaluation of loudness perception performance in cochlear implant users. Biomed Pharmacol J 2015; ‘.;. Doi: 10.13005/ $\mathrm{bpj} / 561$

37 Blamey PJ. Adaptive dynamic range optimization (ADRO): a digital amplification strategy for hearing aids and cochlear implants. Trends Amplif 2005;9(02):77-98 